\title{
Interactive comment on "What are the benefits of lidar-assisted control in the design of a wind turbine?" by Helena Canet et al.
}

Helena Canet et al.

carlo.bottasso@tum.de

Received and published: 5 July 2021

Please see attachments

Please also note the supplement to this comment:

https://wes.copernicus.org/preprints/wes-2020-131/wes-2020-131-AC1-

supplement.pdf

Interactive comment on Wind Energ. Sci. Discuss., https://doi.org/10.5194/wes-2020-131, 2020. 